Digital Simulations as Approximations of Practice: Preparing Preservice Teachers to Facilitate Whole-Group Discussions of Controversial Issues

\author{
Sarah Kaka \\ Ohio Wesleyan University \\ sjkaka@,owu.edu \\ Joshua Littenberg-Tobias \\ Massachusetts Institute of Technology \\ jltobias@mit.edu \\ Taylor Kessner \\ Arizona State University \\ tkessner@asu.edu \\ Anthony Tuf Francis \\ Oakland University \\ akfranci@oakland.edu \\ Katrina Kennett \\ University of Montana Western \\ Katrina.kennett@umwestern.edu \\ G.Marvez \\ Massachusetts Institute of Technology \\ marvezgr@gmail.com \\ Justin Reich \\ Massachusetts Institute of Technology \\ jreich@mit.edu
}


Digital Simulations as Approximations of Practice: Preparing Preservice Teachers to Facilitate Whole-Group Discussions of Controversial Issues

\begin{abstract}
The public schoolhouse is one of the few remaining public spaces in which citizens may routinely gather to discuss controversial issues. Furthermore, it is social studies classrooms and teachers, in particular, that bear the moral imperative to ensure such civic discourse takes place. Nevertheless, many social studies teachers refrain from centering such discussions in their classrooms, often for fear of reprisal should these discussions go awry. It thus falls to social studies teacher educators to rethink how we prepare future teachers. This paper reports on a study that incorporated digital simulations of controversial issues into three preservice social studies teacher preparation methods courses to help develop high-leverage practices associated with leading whole-group discussions. Case study analysis suggests participants developed greater fluency with the teacher moves they practiced in the simulation. Accordingly, participants' developed greater confidence with and perceived importance of facilitating discussions of controversial issues in their future classrooms. Implications and directions for future research are discussed.
\end{abstract}

Funding provided by the Hewlett Foundation 
Discussion and deliberation are bedrocks of a healthy democracy. It follows, then, that engaging in discussions and deliberations on controversial issues ought to be a key component of a democratic education. Those who heed Dewey's (1916) call to engage in discussion around issues of public interest - what he identified as a foundational purpose of educating for democracy - must develop the skills to engage in discussion around contentious issues. These classroom discussions are essential as schools are one of the few public places where students encounter structured opportunities for civic discourse and which require students to confront different points of view and evaluate evidence to support those views (Hess, 2009). However, particularly in the current hyper-partisan political environment, teachers may be hesitant to broach controversial topics in their classrooms for fear of student disruptions and parent pushback (Rogers et al., 2017). Research has highlighted evidence of this discomfort, even at the preservice level (Misco \& Patterson, 2007), suggesting a need - and an opportunity - to focus on the preparation of preservice teachers' (PSTs) framing and skills for facilitating controversial issues.

Facilitation of a classroom discussion is a complex practice requiring a suite of technical sub-skills including setting and enforcing norms, balancing classroom participation, teaching and rewarding the use of constructive dialogue strategies by students, and using effective questioning strategies (Beck, 2005; Crocco et al., 2018; Hess, 2009; McAvoy \& Hess, 2013). While some of these strategies can be prepared in advance, in-the-moment facilitation of classroom discussions is an improvisational endeavor, requiring the adaptive--rather than strictly technical--expertise, to flexibly respond to the context and character of each discussion (Wetzel et al., 2015). Learning experiences that build practitioners' self-awareness of their own practices can improve this 
adaptive expertise (Anthony et al., 2015), thus better preparing PSTs to facilitate these types of discussions.

In this study, we introduce the concept of using digital simulations or 'practice spaces' to prepare teacher candidates to facilitate conversations of controversial issues. These practice spaces are digital approximations of real-life professional scenarios that leverage mixed media-videos, images, text, and audio--to enable professional novices to take part in interactive cycles of practice, reflection and feedback in low-stakes environments (Reich et al., 2018)

Digital simulations are a well-established tool for building expertise across a wide range of fields and disciplines (Aldrich, 2009). For our purposes here, we define simulation as a learning experience designed to approximate a real-world context in which approximations of phenomena can be experienced by participants, and which responds in some substantive way to participants' actions. In this way, participants can assess an authentic teaching situation, plan and take actions, and reflect on the feedback the simulation provides in the form of outcomes tied directly to participants' actions. This reflection in turn informs participants' assessment of future situations and the actions they plan and take, as well as how they reflect on the outcomes of those decisions. Although teaching simulations have shown promise as a method of improving preservice teacher practice, existing platforms, such as Mursion, TLE TeachLive, TeachMe, and simSchool virtual classrooms, incorporate live actors which can be cost- and resource-prohibitive for many teacher education programs (Lindgren et al., 2016). Fully digital simulations may offer a less resource-intensive method for scaling simulations within teacher education, granting PSTs greater access to high-quality educational opportunities and allowing them to improve their adaptive expertise through experience. 
This multiple-case design case study (Yin, 2018) explored how three teacher preparation courses incorporated Discussion Leader, a digital practice space focused on facilitating classroom discussions of controversial issues, into their secondary social studies methods courses. The goal of using Discussion Leader was to help preservice social studies teachers develop adaptive expertise in facilitating discussions of controversial issues. Two specific research questions drove our study:

A. What questions of practice emerged about leading discussions of controversial issues after completing the digital simulations, and how do PSTs reflect on them?

B. What was PSTs' level of confidence in utilizing the high-leverage practice of facilitating whole group discussions of controversial issues before and after completing the instructional activities with embedded Discussion Leader simulations?

\section{Framing the Study}

In this section, we coordinate literature from history and social studies education, as well as from the cognitive and learning sciences. In particular, we highlight the vital role classroom discussion plays in educating for democracy, the challenges to integrating this practice, and how simulations can be used to accelerate learning by developing adaptive expertise.

\section{Discussion of Controversial Issues in Social Studies}

Planning discussions on controversial issues involves selecting topics that are still 'open'; meaning that there is a lack of broad consensus about the right answer (Hess, 2009). Advocates for teaching controversial issues identify three main benefits of discussing controversial issues: viewpoint expansion, deliberation across differences, and creating an open classroom climate.

Discussing controversial issues exposes students to positions they might not otherwise encounter and forces them to consider alternative viewpoints (Hess, 2009). Research on political 
discussion has found that when individuals with different viewpoints discuss issues, they each develop a more complex understanding of political issues than if they discussed the issue only with like-minded individuals (Mutz, 2002) and are more likely to become politically engaged (Kawashima-Ginsberg \& Junco, 2018).

Discussing controversial issues invites students to deliberate across differences.

Deliberative democracy emphasizes active participation of citizens in group decision-making processes to determine the most fair response to a political issue (Beck, 2005; McAvoy \& Hess, 2013). Classroom educators can model deliberative skills by encouraging students to listen to other perspectives and build off each other's comments rather than trying to 'win' the debate (Beck, 2005). Building these skills can help students develop into more effective deliberative civic actors as adults (Kawashima-Ginsberg \& Junco, 2013).

Finally, discussions of controversial issues contribute to an 'open classroom climate' where students feel empowered to raise dissenting viewpoints and disagree with their teacher and other students (McAvoy \& Hess, 2013). For example, Students who report that they could engage in open discussion with their teacher and peers had higher levels of civic knowledge and civic engagement (Torney-Purta, 2002).

\section{Challenges to Teaching Controversial Issues in the Classroom and the Role of Adaptive}

\section{Expertise}

Educators aiming to teach controversial issues face significant challenges and must plan carefully for discussions. Educators cannot assume that they can launch into discussions of controversial issues without having prepared students in advance (McAvoy \& Hess, 2013). However, even with the best-laid plans, discussion of controversial issues can go awry. Discussions may drift toward personal attacks and overgeneralizations and students may feel 
targeted or bullied (Beck, 2005). Parents may protest and accuse the teacher of 'politicizing' the classroom (Kawashima-Ginsberg \& Junco, 2013). Comments during discussions can also have disproportionate effects on students based on their background (Crocco et al., 2018).

Educators who can effectively navigate facilitations of controversial issues need to have 'adaptive expertise'; or the ability to respond flexibly to changing circumstances (Wetzel et al., 2015). For example, educators need to be able to recognize the moments when they need to intervene in a conversation to keep it from spiraling out of control and when they should step back to allow students to work it out on their own. They need to be able to recognize how to frame a question so students engage in deliberation toward a common goal rather than 'winning' the perceived debate. Although there are some patterns educators can look for, the specific contours of these situations change with each set of students. Adaptive expertise helps educators recognize how to respond flexibly in the moments to new types of challenging situations.

\section{Theoretical Framework: The Role of Digital Simulations in Preparing Preservice Teachers To Engage in Complex, High Leverage Practices}

Grounded in practice-based teacher education, as a way to best assist PSTs in becoming effective teachers (Grossman, 2018), this study examined the 'core' (Grossman, 2018) or 'highleverage' practice of leading a whole-group discussion (Ball \& Forzani, 2011). High-leverage practices are "those activities of teaching which are essential. . .competent engagement in them would mean that teachers are well-equipped to develop other parts of their practice and become highly effective professionals" (Ball \& Forzani, 2011, p. 19). Developing these high-leverage practices requires deliberate attention to novice teachers' experiences during the nascent stages of their development. 
A generally accepted proposition in education is that people learn through having experiences and reflecting on those experiences (e.g., Gee, 2017). In teacher education, this often means reflecting on preservice field experiences (Wetzel et al., 2015). True novices to the profession, however, have neither the prior experiences to inform such reflection, nor access to new ones without accepting a high level of risk of failure in the course of apprenticeship. Moreover, learning through experience is often slow, prone to error, and difficult to predict in terms of specific learning goals.

Approximations of practice provide opportunities for novices to engage in practices proximal to the practices of a profession (Grossman et al., 2009). Approximations of practice include purposeful and effortful activities that PSTs engage in with the sole intent of improving their teaching performance by allowing them to experience instructional successes and failures in a safe environment (Grossman, et. al., 2009). Centering approximations of practice allows teacher educators to provide deliberately scaffolded opportunities for PSTs to target practices in escalating degrees of authenticity over time.

As a method for approximating practice, simulations direct participants to specific aspects of classroom scenarios. Gee (2017) describes these types of learning experiences as +experiences. +Experiences are learning activities in which (a) learners have actions to take; (b) they care about the outcomes of those actions; and (c) a more-knowledgeable other or structural equivalent within the learning design helps learners know what elements of the experience are important to direct attention.

Simulations in teacher education need not be digital. Dotger \& Ashby (2010) designed clinical simulations where PSTs interact with trained actors in a semi-scripted scenario. Others have employed digital avatars controlled by human actors that provide the illusion of interacting 
with multiple students in a classroom (Kannan et al., 2018). These non-digital and mixed-reality forms of simulations can be effective in approximating different aspects of teaching for novices. However, they are expensive and logistically complex to implement.

Fully digital simulations, what we refer to as 'practice spaces' (Reich et al., 2018) have a number of potential affordances which makes them useful for integration within teacher education programs. Those within web applications are relatively inexpensive to produce and disseminate, providing opportunities for repeated, targeted practice on specific teaching skills. Additionally, digital simulations can be easily adapted to fit the specific needs of the PSTs or in response to particular events in the news. For example, Sullivan et al., (2020) designed a set of simulations around responding to student trauma in the aftermath of the initial spike of the COVID-19 pandemic.

Nevertheless, we acknowledge the limitations of digital simulations. Although there is some evidence that participants find the situations themselves to be authentic, the simulations are not always representative of the complexities of the classroom (Thompson et al., 2019). Additionally, maintaining balance between accessibility for novices and authentically representing real-life practice may necessitate the oversimplification of aspects of teaching. Digital simulations are therefore a complement, not a substitute, for 'live' approximations of practice or for clinical preparation in classrooms. However, we believe digital simulations lay the groundwork for increasing PSTs' attention to their practice.

We posit digital approximations of practice lead to increases in PSTs' confidence, and that teachers who are more confident in their ability to carry out a pedagogical strategy--in this multiple-case design case study facilitating discussion of controversial issues--are more likely to employ that strategy in their practice over the long term. Increases in confidence can be linked to 
opportunities afforded by the learning environment to experience feelings of competence, which research shows is a primary driver of intrinsic motivation (Ryan \& Deci, 2000). Furthermore, what PSTs later do in their classrooms can be predicted by the dispositions they develop during their formative preparation years. Through repeated participation in learning experiences like the digital simulation we describe, PSTs develop the ability to use high-leverage teaching practices, the sensitivity required to recognize when such practices are useful, and the inclination to incorporate them into their practice (Perkins et al., 2000).

In this study, we use the frameworks of approximation of practice and experience to explore the affordances of digital simulations within teacher education to facilitate whole group discussions on controversial issues. We aim to identify the potential affordances of this technology by examining how students experience the same set of digital simulations within three different teacher preparation programs. In our analysis, we sought to identify whether the digital simulations were able to elicit examples of participants engaging in questions of practice. Additionally, we were interested in whether participants perceived the simulations as useful in helping them gain confidence in engaging in complex teaching behaviors with students. As such, we sought to explore the answer to two questions: What questions of practice emerged about leading discussions of controversial issues after completing the digital simulations, and how do PSTs reflect on them? What was PSTs' confidence in utilizing the high-leverage practice of facilitating whole group discussions of controversial issues before and after completing the instructional activities with embedded Discussion Leader simulations?

\section{Rationale for the Study}

Our first research question explores pre-service teachers' emerging questions and reflection on leading a group discussion after their interaction with the digital simulation. This 
question combines knowledge of research on digital simulations (Aldrich, 2009), facilitation of whole class discussions (Beck, 2005; Crocco et al., 2018), and teaching controversial issues (Hess, 2009; McAvoy \& Hess, 2013). Examining PSTs' questions about how to effectively lead a class discussion helps us better understand whether or not the digital simulation learning experiences did in fact build their self-awareness of their own practices.

Our second question explores the impact of participating in Discussion Leader, a digital simulation, on PSTs' confidence to lead a discussion on controversial issues. We were interested in confidence because, as we stated earlier, teachers who are more confident in their ability to lead discussions are more likely to do so in their classroom. Considering the critical and contentious nature of these discussions in the social studies classroom, focusing our inquiry on confidence was one dimension to measure the effectiveness of Discussion Leader.

This study is not intended to make any causal claims regarding the effectiveness of the simulation on teacher preparation, as there is no control or comparison group. Rather, it is intended to examine the outcome of the simulation's effect on these students and their preparedness to engage in leading whole class discussions of controversial issues. Similarly, because findings from case studies are not in and of themselves generalizable (Yin, 2018), we do not make claims to generalizability. Nevertheless, due to the multiple-case design (Yin, 2018, p. 48), we do contend our findings are more likely to be transferable across contexts. Thus, our argument is as follows: (1) authentic practice-based experience is vital in the preparation of PSTs to facilitate whole-class discussion of controversial issues, but (2) such experiences are inequitably available across socioeconomic and geographic contexts, and therefore, (3) the affordances of digital simulation practice spaces may broaden access to such experiences as well as supplement them. 


\section{Methods}

In order to explore PSTs' perceptions of their confidence and their thoughts about utilizing the high-leverage practice of facilitating whole group discussions of controversial issues after participating in a learning experience that incorporates digital practice spaces, we conducted a qualitative multiple-case design case study (Yin, 2018). This study design was appropriate as it allowed us the opportunity to explore the issue by using specific cases within a real-life setting and provided insight into their experiences through analysis of focus group conversations, observations, and other artifacts across different contexts (Patton, 2015; Yin 2018). The themes and patterns that emerge from data collection and analysis allow us to make generalizations about the case as well as lessons learned from the study (Yin, 2018). Our case for this study was the group of social studies PSTs across the three institutions in their social studies methods class the semester before student teaching. While this paper is primarily qualitative, we included a quantitative indicator of confidence to triangulate our qualitative findings.

\section{Simulation Design}

Discussion Leader is a digital practice space on facilitating discussions of controversial issues in K-12 classrooms (https://tsl.mit.edu/practice_space/discussion-leader/). It is a web application that was built using Twine Sugarcube, a platform that allows users to build interactive narratives. For this project, PSTs participated in two versions of Discussion Leader: “Discussion Leader: Immigration," which focused on immigration policies, and "Discussion Leader: Gun Violence,” which focused on gun control policies. All versions of Discussion Leader follow the same basic format: (1) Context, (2) Anticipate, (3) Enact, and (4) Reflect. In the 'Context' phase, participants are introduced to their three students, each of whom represents a different viewpoint on the issue. They then are provided background information on 
how their teacher-character has prepared the students for today's discussion, including relevant readings. Next, participants are asked a series of open-response 'Anticipate' questions that elicit their goals for the discussion.

Participants then start the 'Enact' phase, where they are shown a student dialogue vignette and are asked how they would respond to that particular prompt (see Figure 1). Participants are given 2-3 response options for each vignette. Based on what response they select, a new vignette then appears. Each choice the participants make alters the path through the simulations. Discussion Leader was intentionally designed as a teaching tool, and as such, some of the options were written explicitly to reflect poor instructional choices (i.e. allowing conversations between students to get overly heated or ignoring statements offered without evidence). The simulation is designed so that when the participant makes poor choices, potential consequences of these choices are reflected in the student dialogue.

Participants conclude the simulation with the 'Reflect' where they are asked about whether they achieved their goals within the simulation and what they might do differently in the future. Altogether, the simulation takes about 20-30 minutes. 


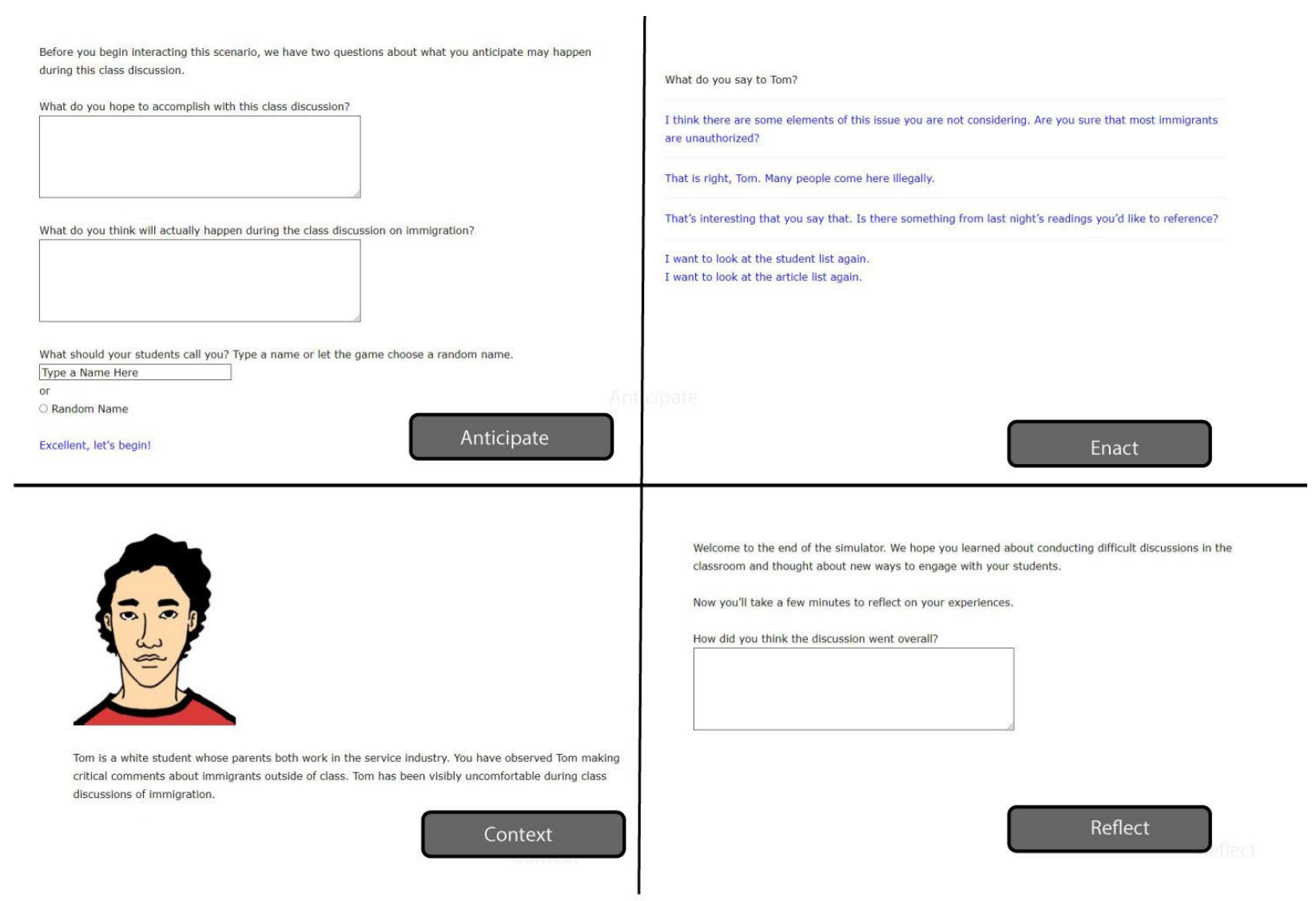

Figure 1. Screenshots from Discussion Leader: Immigration

Earlier in the paper, we discussed the limitations of digital simulations broadly. Here we focus on limitations specific to Discussion Leader. First of all, there are only three 'students' with which the pre-service teacher engages, as opposed to a whole class, and the personalities and reactions of these three students are inevitably limited. Second, the nature of the multiplechoice format limits the unpredictability of working with real human beings in real time. Though the choices have been vetted by numerous professional teacher educators, it is difficult to simulate the multitude of potential outcomes that occur within a discussion. Finally, the reflection PSTs do at the end is limited in that it is little more than speculation by a novice teacher based on a highly-structured activity. Regardless of these limitations, we believe that 
Discussion Leader serves well as an approximation of practice for novice teachers learning to lead a group discussion.

\section{Participants}

The study utilized data from three different social studies teacher preparation programs: one large public R1 institution; one small private liberal arts institution; and one mid-size public institution. A total of 35 PST participants were enrolled in a semester-long social studies methods class at the time of data collection. The demographic details of each site are seen in Table 1.

Table 1

Study Site Demographics

\begin{tabular}{|c|c|c|c|}
\hline & $\begin{array}{l}\text { Site } 1 \\
\mathrm{n}=10\end{array}$ & $\begin{array}{l}\text { Site } 2 \\
\mathrm{n}=13\end{array}$ & $\begin{array}{l}\text { Site } 3 \\
\mathrm{n}=12\end{array}$ \\
\hline $\begin{array}{l}\text { Type of } \\
\text { institution }\end{array}$ & $\begin{array}{l}\text { Large public R1 } \\
\text { institution }\end{array}$ & $\begin{array}{l}\text { Midsize public } \\
\text { institution }\end{array}$ & $\begin{array}{l}\text { Small private liberal arts } \\
\text { institution }\end{array}$ \\
\hline Degree pursued & $\begin{array}{l}\text { Master's degree with } \\
\text { licensure or post- } \\
\text { baccalaureate } \\
\text { licensure }\end{array}$ & $\begin{array}{l}\text { All undergraduates but } \\
\text { one, completing 5-year } \\
\text { degree and licensure } \\
\text { program }\end{array}$ & All undergraduates \\
\hline $\begin{array}{l}\text { Amount of class } \\
\text { time }\end{array}$ & $\begin{array}{l}\text { Once a week, } 165 \\
\text { minutes }\end{array}$ & $\begin{array}{l}\text { Once a week, } 210 \\
\text { minutes }\end{array}$ & $\begin{array}{l}\text { Once a week, } 110 \\
\text { minutes }\end{array}$ \\
\hline Female & 8 & 4 & 7 \\
\hline Male & 2 & 9 & 5 \\
\hline $\begin{array}{l}\text { Type of } \\
\text { licensure }\end{array}$ & $\begin{array}{l}\text { Secondary (grades 6- } \\
\text { 12) licensure }\end{array}$ & $\begin{array}{l}\text { Secondary social studies } \\
\text { initial license (grades } \\
6-12 \text { ) }\end{array}$ & $\begin{array}{l}5 \text { pursuing middle } \\
\text { childhood licensure } \\
\text { (grades 4-9); } 7 \text { pursuing } \\
\text { secondary licensure } \\
\text { (grades } 7-12 \text { ) }\end{array}$ \\
\hline $\begin{array}{l}\text { Field } \\
\text { experiences }\end{array}$ & $\begin{array}{l}\text { Some but not all in } \\
\text { concurrent field } \\
\text { experience }\end{array}$ & $\begin{array}{l}\text { All in concurrent field } \\
\text { experience }\end{array}$ & $\begin{array}{l}\text { Some but not all in } \\
\text { concurrent field } \\
\text { experience }\end{array}$ \\
\hline
\end{tabular}




\section{Data Collection}

We designed the pedagogical innovation on which we report in this paper according to principles of design-based research, however, this is not a design-based research study. We carried out the intervention in the 'messy' contexts of three separate methods courses, each located at different institutions of higher education (Brown, 1992). Conducting methodologically sound research in real contexts of practice closes this credibility gap by improving inferential reliability (Hoadley, 2004). Furthermore, the fact this research took place in three different institutional settings is perhaps the greatest strength of our research design, by bolstering the analytic and theoretical validity of the claims we make below, thus increasing generalizability (Bakker, 2018).

To collect data for our case, we co-designed a common instructional framework that included two iterative cycles of anticipation, enactment, reflection, and debrief around digital simulations (Figure 2). Faculty implemented two modules of Discussion Leader with their PSTs. Data included pre-and-post assessments, written reflections within the simulation, and transcribed audio recordings of methods class debriefs used as focus groups. Focus groups were structured as informal discussions among selected individuals about specific topics (Beck et al., 1986). We used these qualitative data sources per Miles et al.'s (2019) advice regarding triangulation of sources to support inferences.

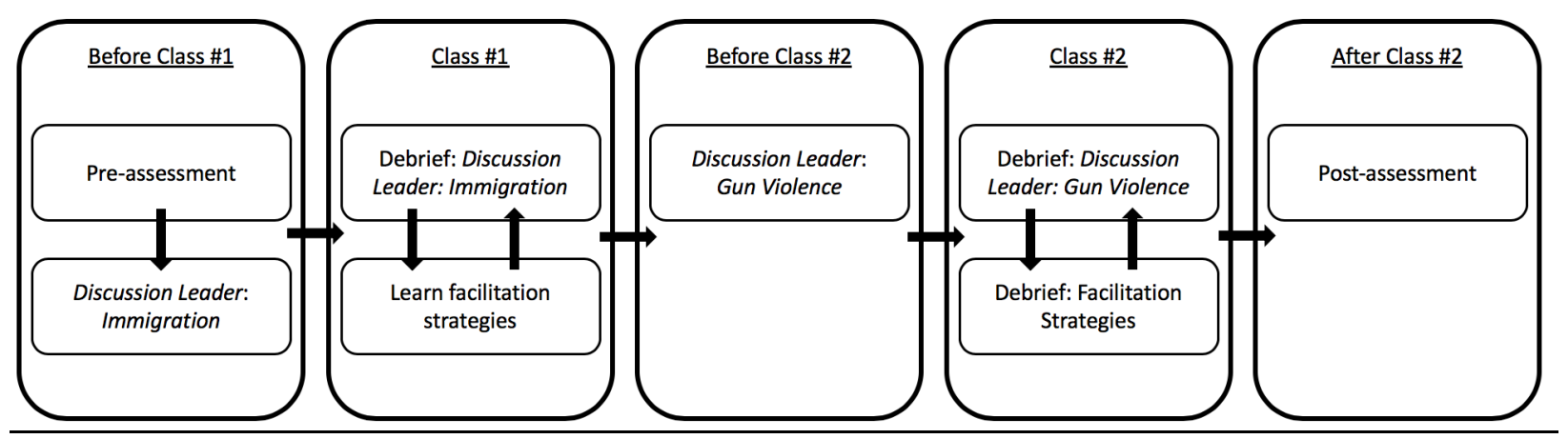




\section{Figure 2. Common Instructional Activities Incorporating Digital Simulations}

Before engaging in the Discussion Leader practice space, participants completed a preassessment that asked them to describe the elements of a successful discussion, the skills and knowledge that teachers need to facilitate discussions of controversial issues, and how teachers learn these skills. The pre-assessment also asked them to rate their current confidence in facilitating class discussions of controversial issues using a Likert scale of 1 (not confident) to 5 (very confident).

After the PSTs took the pre-assessment, they completed one iteration of the Discussion Leader practice space which positioned them as teachers leading a discussion on immigration in a high school history classroom in a diverse high school with opinionated students. In the practice spaces, participants first reviewed facts and data presented to them about immigration, then met their diverse students. Participants were asked two pre-simulation questions about what they hoped to accomplish in the simulation and what they thought would actually happen during the class discussion. Participants then worked through the simulation, choosing the options as if they were a teacher leading the discussion. Post practice-space, they reflected on how their discussion went and whether or not they accomplished what they set out to before completing the simulation.

The PSTs then attended class, where the instructor led a debrief on their Discussion Leader simulation experience, further digging into their rationale for why they chose what they did and what they wish they would have done differently. The instructors then taught strategies to facilitate discussions and assigned readings as desired. They also assigned the students to complete a second Discussion Leader online simulation before the next class, this one on the 
topic of gun violence. The gun violence simulation included the same style of pre-simulation assessment and post-simulation reflection as the immigration simulation.

The PSTs returned to class and participated in another class debrief on the ways in which they used the facilitation strategies taught in the previous class. They were asked to justify their choices in the simulation and make connections about their choices based on the readings and previous class discussion. Finally, PSTs completed a post-assessment that mirrored the preassessment, and included additional reflection questions about what they learned from the Discussion Leader simulation.

\section{Data Analysis}

Both inductive and deductive data analyses were performed (Yin, 2018), and the data was coded in cycles using in vivo coding methods (Miles et al., 2019). Qualitative pre-assessment and post-assessment responses, class debriefs, and qualitative Discussion Leader pre- and postsimulation data were all reviewed and initial codes were formed prior to analysis in Dedoose, a qualitative data analysis software. Once patterns and themes were established through inductive

analysis, deductive analysis was completed to affirm the authenticity of the inductive analysis (Patton, 2015).

During the first cycle of inductive coding, in vivo and evaluative codes were created from the data by each individual researcher. Examples of in vivo codes, which use the participants' own language, include 'students' knowledge and skills' and 'role of the teacher.' In addition, researchers created memos throughout coding, taking notes on emerging themes and patterns (Miles et al., 2019). During the second cycle of coding, the results of the individual researchers' codes were compared and final themes and patterns were identified through further review and memoing (Yin, 2018). See Table 2 for associated codebook. 
Table 2

Codebook

\begin{tabular}{|c|c|c|c|}
\hline Code & Definition & Typical Exemplar & Atypical Exemplar \\
\hline $\begin{array}{l}\text { Classroom } \\
\text { Climate }\end{array}$ & $\begin{array}{l}\text { This code refers to the } \\
\text { importance of } \\
\text { establishing a } \\
\text { classroom climate that } \\
\text { is conducive to } \\
\text { discussing controversial } \\
\text { issues }\end{array}$ & $\begin{array}{l}\text { I think posting reminders about } \\
\text { properly contributing to } \\
\text { discussions around the } \\
\text { classroom is vital. Also, } \\
\text { instilling classroom } \\
\text { management protocols and } \\
\text { procedures should be in place } \\
\text { ahead of time before } \\
\text { interactive activities, like } \\
\text { discussions, begin. Like Wong } \\
\text { mentioned in his book, "Be } \\
\text { proactive and not reactive." }\end{array}$ & $\begin{array}{l}\text { Foster a classroom } \\
\text { environment where } \\
\text { students feel challenged, } \\
\text { but safe to voice divergent } \\
\text { opinions and bring forward } \\
\text { new civic topics for } \\
\text { consideration and critique. }\end{array}$ \\
\hline $\begin{array}{l}\text { Role of the } \\
\text { Teacher }\end{array}$ & $\begin{array}{l}\text { This code defines what } \\
\text { participants believe the } \\
\text { role of the teacher is in } \\
\text { leading a discussion } \\
\text { about a controversial } \\
\text { issue }\end{array}$ & $\begin{array}{l}\text { Provide discussion norms, } \\
\text { create civil discourse, } \\
\text { background knowledge on the } \\
\text { content, and determine their } \\
\text { place in the discussion (what } \\
\text { role they will play). }\end{array}$ & $\begin{array}{l}\text { I just think it's important to } \\
\text { teach people a moderate } \\
\text { stance as well. But that's } \\
\text { politics. }\end{array}$ \\
\hline $\begin{array}{l}\text { Students: } \\
\text { Knowledge } \\
\text { and skills } \\
\text { needed }\end{array}$ & $\begin{array}{l}\text { This code explores what } \\
\text { knowledge and skills } \\
\text { participants believed } \\
\text { are important for } \\
\text { students to have in } \\
\text { order to successfully } \\
\text { participate in a } \\
\text { discussion about a } \\
\text { controversial issue }\end{array}$ & $\begin{array}{l}\text { Students need to know how to } \\
\text { assess sources, determine } \\
\text { what arguments work, then } \\
\text { organize facts into persuasive } \\
\text { arguments. }\end{array}$ & $\begin{array}{l}\text { And kind of have that sense } \\
\text { of like agree-to-disagree } \\
\text { almost. Like it's okay that } \\
\text { we don't agree, but I accept } \\
\text { that you have a different } \\
\text { perspective than I do, but } \\
\text { we can still have, you } \\
\text { know, a mutually } \\
\text { respectful relationship. }\end{array}$ \\
\hline $\begin{array}{l}\text { Teachers: } \\
\text { Knowledge } \\
\text { and skills } \\
\text { needed }\end{array}$ & $\begin{array}{l}\text { This code explores what } \\
\text { knowledge and skills } \\
\text { participants believed } \\
\text { are important for } \\
\text { teachers to have in } \\
\text { order to successfully } \\
\text { lead a discussion about } \\
\text { a controversial issue }\end{array}$ & $\begin{array}{l}\text { The teacher should be prepared } \\
\text { with background information } \\
\text { on the different views on the } \\
\text { topic that may come up during } \\
\text { the discussion. }\end{array}$ & $\begin{array}{l}\text { It is unlikely, but you could } \\
\text { have a class of students } \\
\text { that mostly agree with one } \\
\text { another so the opposing } \\
\text { viewpoint struggles to } \\
\text { emerge. Being able to } \\
\text { ensure that all sides are } \\
\text { heard is important. }\end{array}$ \\
\hline
\end{tabular}

\section{Findings}


We begin our findings section with a quantitative overview of the results of our qualitative coding, using the codes from the second cycle of coding as seen in Table 3 below. We advance to reporting participants' changes in confidence following their engagement with Discussion Leader. We then describe participants' evolving attitudes regarding the knowledge and skills they need to perform their professional duties as social studies teachers.

\section{Table 3}

Code Counts

\begin{tabular}{|l|l|}
\hline \multicolumn{1}{|c|}{ Code } & \multicolumn{1}{c|}{ Count } \\
\hline Classroom Climate & 14 \\
\hline Role of the Teacher & 15 \\
\hline Students: Knowledge and skills needed & 14 \\
\hline Teachers: Knowledge and skills needed & 25 \\
\hline
\end{tabular}

\section{How did PSTs' confidence in utilizing the high-leverage practice of facilitating whole group} discussions of controversial issues change after completing the Discussion Leader modules?

Initial evidence suggests that participating in Discussion Leader helped PSTs develop confidence about their practice and become more reflective about their own performance--which we have argued is a crucial step toward developing facilitation expertise.

In our analysis of the pre-assessment data, we found that PSTs were initially less confident in their knowledge of leading a discussion and the skills needed to do it. They cited anxiety and stress, and a desire to minimize confrontation among students. One participant said, "I don't know how far the simulation actually went, because I kept trying to just choose the answers that were [most likely] to like, shut it down," indicating a sense of fear that the discussion would get out of hand. When asked in the pre-assessment to rate their confidence in 
their ability to facilitate a discussion on a controversial issue, with one as 'not confident', and five 'very confident,' the mean was 2.83 out of five.

After completing the instructional unit as outlined in the Methods section, participants were asked again to rate their confidence in their ability to facilitate a discussion on a controversial issue. The mean of the post-survey was 3.64, an almost 1-point increase on the 5point scale. The difference was statistically significant $(t(59)=3.577, p<0.001)$, and had a Cohen's $d$ effect size of 0.94 . In the subsequent post-assessment and debrief, the desire to "shut it down" lessened, and some students indicated making choices in the simulation in order to "stir the pot" to better test their own skills at how to manage the discussion. One participant noted that they, “...did want it to escalate while still looking to see when it would get that intense vibe I guess...I [was] thinking about it more, analyzing the choices [in the simulation].”

In addition to the findings on change in confidence, three main questions of practice emerged surrounding the high-leverage practice of leading whole-group discussions as a result of data coding and analysis.

\section{What are the PSTs' perceptions of the role of the teacher in facilitating discussions?}

During the in-class debrief, students identified four roles of the teacher in facilitating the discussion based on their experience in the practice space $(n=15)$. First, they believed it is the teacher's job to create a positive classroom environment. They felt that a teacher should "instill classroom management protocols and procedures...ahead of time before discussions begin." This should stem from a "good set of rules showing the students what they can not say and that there will be no tolerance for students saying these things."

Additionally, PSTs saw the role of the teacher in the practice space as that of facilitator, or leader of, the discussion. They believed that the teacher needed to 'keep the discussion "on 
track" and be able to "read their students" if they are getting too fired up or too uncomfortable. Ultimately, teachers were perceived to be the mediator that allows "students the opportunity to form their opinions and be heard."

Some PSTs indicated that during the practice space, it was the role of the teacher to actually create tension in the classroom. One said, "I like argument, I think it is good," and that it can be helpful to play devil's advocate, especially when "nobody else takes the other side." This forces students to "back up ideas with evidence."

Finally, PSTs felt that in the practice space, the teacher's role was to model discussionrelated best-practices and behaviors so that their students would better understand "the right things and wrong things to say in a discussion." Along those lines, teachers needed to model how best to be "an unbiased presence" to more effectively support their students' abilities in putting aside their own biased perspectives.

\section{What knowledge and skills do participants perceive as important for teachers in order to facilitate these discussions?}

PSTs cited a variety of knowledge and skills needed by teachers to successfully lead a classroom discussion about a controversial issue $(\mathrm{n}=25)$. PSTs cited a need to know their students. "Teachers should know a rough background of their students so they know if the issue at hand might be a trigger for them or not." If a topic were to "trigger" a student, the teacher's ability to manage their classroom would potentially be tested. Therefore, teachers must have strong classroom management knowledge and skills in order to "control the classroom."

PSTs also described the importance of a teacher's content knowledge about the issue being discussed. They needed to "be very knowledgeable about these topics so that you can relate to both sides of the argument" but also have strong knowledge of the issue to "understand 
where the flash points on the topic will be." Knowledge of equity and social justice, patience, empathy, an ability to understand other points of view, and an ability to demonstrate respect for others were also all cited. Teachers needed to be able to "teach your students to have that openmindedness," and drive the discussion in a productive direction and know when it is necessary and appropriate to intervene and get the conversation back on track. Teachers needed to know "when to let the students keep talking [and have an] understanding of when the tension is getting too high."

\section{What knowledge and skills do PSTs perceive as important for students to have in order to participate in these discussions?}

PSTs believed that there was certain knowledge and skills their students needed in order for them to facilitate a successful whole-group discussion $(\mathrm{n}=14)$. Students needed to adhere to discussion procedures and protocols as outlined by their teacher in order to support a mature discussion. Students needed to have the skills to be respectful to their peers, even in the midst of a heated discussion.

Students also needed to have the ability to be open-minded and see other perspectives. PSTs felt that students need to "accept that you have a different perspective than I do, but we can still have, you know, a mutually respectful relationship."

Finally, the PSTs believed that it was important for students to know how to "assess sources, determine what arguments work, then organize facts into persuasive arguments." From there, students should have the skills and knowledge to both ask and answer, "okay, so show me your evidence. Provide your, what's your support for this statement that you're making?" 


\section{Limitations}

The ways in which the whole class debrief focus groups were structured has the potential to be a limitation. Although we focused on the same general questions, the exact content of the debriefs varied by instructor, and some classes spent more time and went further into depth debriefing the simulation than others. The makeup of our classes contributed to this variation as some were undergraduate students while others were graduate or post-baccalaureate. The variation in focus group size was also a potential limitation, as the classes ranged in size from five students to thirteen. While there may be an argument for viewing these as three separate cases because our unit of analysis did not include each instructor's facilitation techniques, we approached this as one case of implementing Discussion Leader, and the accompanying teaching and learning ecology design in three different contexts.

As stated earlier, this study does not measure the effectiveness of the digital simulations, but instead examines PSTs' experiences with, and their perceptions of what they learned completing the unit that included the use of them. We did not measure a causal relationship between the use of the simulation as a teaching tool as there was no control group, which is an additional limitation.

\section{Discussion}

Although simulations are a promising method for helping PSTs improve their practice (Dotger \& Ashby, 2010), there is limited empirical research on how social studies teachers experience these simulations. In this study, we demonstrated that simulations can offer meaningful starting-points for PSTs in social studies to both gain confidence as they apprentice into leading discussions and to reflect on emergent questions of practice. 
Discussion Leader allowed participants to slow down the pace of a discussion and attend closely to select moves they could make. The available moves, which an experienced teacher makes in relation to the pace and emerging social situation of the classroom conversation, previewed both technical and social skills PSTs will need. As with approximations of practice (Grossman et al., 2009), integrating the simulation into existing classes provided opportunities for PSTs to reflect on their own choices, observe the rationales of their classmates, and triangulate with course readings. After going through the simulations, PSTs were able to break down a novel situation, consider multiple pathways forward, and reason through the consequences of their choices.

With that said, based on their experiences in the simulation, PSTs identified limited roles, knowledge, and skills that teachers need to effectively lead discussions on controversial issues. Their reflections showed them positioning themselves at the hub of the discussion, prodding students for more information, framing purposes, and inviting civil stances. They did not discuss encouraging deliberation between students which might have improved the quality of discussion overall (Beck, 2005).

Other features of facilitation, especially ones based on responsiveness to students, constructivism, and/or cultural responsiveness, also did not appear in the PSTs' responses. For example, the PSTs did not identify ways that teachers could allow students to share power with students by, for instance, working together to construct shared norms, or sharing their own opinions and beliefs (Hess, 2009). They also did not discuss their own positionality or the positionality of the students in terms of how different are differentially impacted by controversial issues such as gun violence or immigration (Crocco et al, 2018). This suggests that while the simulations elicited students' understanding of practice, they did not sufficiently push to consider 
more student-centered approaches to teaching controversial issues. Because the PSTs were the only 'real' agents that could make choices within Discussion Leader, the simulation did not reproduce the dynamics of trying to facilitate discussions with more student-centered approaches. Future studies need to be completed to better gauge the effectiveness of digital simulation tools, and their impact on teacher preparation. This should include the examination of a causal relationship that measures the effect of the simulations on teachers' knowledge, attitudes, and performance in the classroom.

\section{Moving Forward}

Discussion Leader offers participants a highly constructed simulated environment to prepare for what can be a highly sensitive and potentially charged real life situation. The practice space can play a pedagogical role for teacher educators as they engage PSTs in nuanced discussions around an interactive, yet still common text. In our conversations around Discussion Leader, we have deeply considered the profiles of the fake students - what do they say and draw upon that novice teachers should 'pick up on'? What does it look like for teacher educators to build on PSTs' choices? Creating the boundary-spanning digital space for this scenario and embedding the opportunity to practice high-leverage practices offer future teachers apprenticeship into the common lexicon of our profession.

As we look to improve Discussion Leader, we are considering options for visual indicators of what teachers should be on the lookout for in the classroom, things that may be difficult to replicate in an online simulation environment. For example, 'bars' that indicate that the tension in the room is escalating based on the choices they make in the simulation. An alternative to that is a change in the simulation avatars' facial expressions to indicate escalating 
or withdrawing emotions. It is important for teachers to learn how to handle increased tension in the room--how close is the discussion to becoming counterproductive?

Teaching teachers the skills to include all students in a discussion is important as well. Allowing students to feel marginalized or left out of the conversation can be just as detrimental to them as ignoring the tension in the room. How can the simulation better visualize when some students are being excluded so that a teacher can make a more informed choice in the simulation to draw them in? We also have discussed the role emotions play in the scenario - and in real life controversial conversations - and how to respect the variety of feelings that controversial discussions provoke, while still challenging students to learn and show compassion for others.

Finally, we aim to develop multiplayer versions of Discussion Leader that would allow for PSTs to adopt the role of both students and teachers to better approximate student-to-student dialogue. Some possibilities include synchronous chat-based scenarios or turn-based simulations that would allow for multiple pre-service teachers to participate as both students and teachers with the simulation.

\section{Conclusion}

As teacher education programs increasingly leverage emerging digital simulations in practice-based apprenticeships, this practice space model can help PSTs and teacher educators co-construct meaning about the purposes, forms, considerations, and issues with facilitating controversial discussions in the classroom. Together, teacher educators and PSTs can better focus on the fundamental need to pay close attention to students - noticing the needs, moves, and ideas of the students in front of them, and who they could be. 


\section{References}

Aldrich, C. (2009). Learning Online with Games, Simulations, and Virtual Worlds: Strategies for Online Instruction. JosseyBass Guides to Online Teaching and Learning Variation JosseyBass Guides to Online Teaching and Learning.

Anthony, G., Hunter, J., \& Hunter, R. (2015). Supporting prospective teachers to notice students' mathematical thinking through rehearsal activities. Mathematics Teacher Education and Development, 17(2), 7-24.

Bakker, A. (2018). Design research in education: A practical guide for early career researchers. Routledge.

Ball, D. L., \& Forzani, F. M. (2011). Building a common core for learning to teach: And connecting professional learning to practice. American Educator, 35(2), 17-21, 38-39.

Beck, T. A. (2005). Tools of deliberation: Exploring the complexity of learning to lead elementary civics discussions. Theory \& Research in Social Education, 33(1), 103-119. https://doi.org/10.1080/00933104.2005.10473273

Beck, L. C., Trombetta, W. L., \& Share, S. (1986). Using focus group sessions before decisions are made. North Carolina Medical Journal, 47, 73-74.

Brown, A. L. (1992). Design experiments: Theoretical and methodological challenges in creating complex interventions in classroom settings. The Journal of the Learning Sciences, 2(2), 141-178.

Crocco, M. S., Segall, A., Halvorsen, A. \& Jacobsen, R. (2018). Deliberating public policy issues with adolescents. Democracy \& Education (26).

Dewey, J. (1916). Democracy in Education. Macmillan. 
Dotger, B. H., \& Ashby, C. (2010). Exposing conditional inclusive ideologies through simulated interactions. Teacher Education and Special Education: The Journal of the Teacher Education Division of the Council for Exceptional Children, 33(2), 114-130. https://doi.org/10.1177/0888406409357541.

Gee, J. P. (2017). Teaching, learning, literacy in our high-risk high-tech world: A framework for becoming human. Teachers College Press.

Grossman, P. L., Compton, C., Igra, D., \& Williamson, P. W. (2009). Teaching practice: A cross-professional perspective. Teachers College Record.

Grossman, P. (2018). Teaching core practices in teacher education. Harvard Education Press.

Hess, D. (2009). Controversy in the classroom: The democratic power of discussion. Routledge.

Hoadley, C. M. (2004). Methodological alignment in design-based research. Educational Psychologist, 39(4), 203-212. https://doi.org/10.1207/s15326985ep3904_2

Kannan, P., Kannan, P., Zapata-Rivera, D., Mikeska, J., Bryant, A., Long, R., \& Howell, H. (2018). Providing Formative Feedback to Pre-service Teachers as they Practice... Society for Information Technology \& Teacher Education International Conference, 2018(1), $1570-1575$.

Kawashima-Ginsberg, K. \& Junco, R. (2018). Teaching controversial issues in a time of polarization. Social Education, 82(6), 323-329.

Lindgren, R., Tscholl, M., Wang, S., \& Johnson, E. (2016). Enhancing learning and engagement through embodied interaction within a mixed reality simulation. Computers \& Education, 95, 174-187. https://doi.org/10.1016/j.compedu.2016.01.001.

McAvoy, P., \& Hess, D. (2013). Classroom deliberation in an era of political polarization. Curriculum Inquiry, 43(1), 14-47. https://doi.org/10.1111/curi.12000 
Miles, M. B., Huberman, A. M., \& Saldaña, J. (2019). Qualitative data analysis: A methods sourcebook (4th ed.). Sage.

Misco, T., \& Patterson, N. C. (2007). A study of pre-service teachers' conceptualizations of academic freedom and controversial issues. Theory \& Research in Social Education, 35(4), 520-550. https://doi.org/10.1080/00933104.2007.10473349

Mutz, D. (2002). The consequences of cross-cutting networks for political participation. American Journal of Political Science Review, 46, 838-855.

Patton, M. Q. (2015). Qualitative research \& evaluation methods (4th ed). Sage.

Perkins, D., Tishman, S., Ritchart, R., Donis, K., \& Andrade, A. (2000). Dispositions in the wild: A dispositional view of intellectual traits. Educational Psychology Review, 12(3), pp. 269-293.

Reich, J., Kim, Y. J., Robinson, K., Roy, D., \& Thompson, M. (2018, July). Teacher practice spaces: examples and design considerations [Paper presentation]. 13th International Conference of the Learning Sciences, Inc., London, United Kingdom. https://research.utwente.nl/files/102267789/ICLS2018_Volume_1_Final.pdf\#page=688

Rogers, J., Franke, M., Yun, J.-E. E., Ishimoto, M., Diera, C., Geller, R. C., Berryman, A., \& Brenes, T. (2017, October). Teaching and learning in the age of Trump: Increasing stress and hostility in America's high schools. UCLA Institute for Ideas, Democracy, Education, and Access. https://idea.gseis.ucla.edu/publications/teaching-and-learning-inage-of-trump

Ryan, R. M., \& Deci, E. L. (2000). Self-determination theory and the facilitation of intrinsic motivation, social development, and well-being. American Psychologist, 55(1), pp. 6878. 
Sullivan, F., Hillaire, G., Larke, L. \& Reich, J. (2020). Using teacher moments during the COVID-19 pivot. Journal of Technology and Teacher Education, 28(2), 303-313.

Torney-Purta, J. (2002). The school's role in developing civic engagement: A study of adolescents in twenty-eight countries. Applied Developmental Science, 6, 203-212.

Thompson, M., Owho-Ovuakporie, K., Robinson, K. Kim, Y.J., Slama, R. \& Reich, J. (2019) Teacher Moments: A Digital Simulation for Preservice Teachers to Approximate ParentTeacher Conversations, Journal of Digital Learning in Teacher Education, 35:3, 144164, DOI: $10.1080 / 21532974.2019 .1587727$

Wetzel, A. P., De Arment, S. T., \& Reed, E. (2015). Building teacher candidates' adaptive expertise: Engaging experienced teachers in prompting reflection. Reflective Practice, 16(4), 546-558. https://doi.org/10.1080/14623943.2015.1064380

Yin, R. K. (2018). Case study research and applications: Design and methods (6th ed.). Sage. 